\title{
Are risk factors for atherothrombotic disease associated with back pain sickness absence? The Whitehall II study
}

Harry Hemingway, Martin Shipley, Stephen Stansfeld, Harry Shannon, John Frank, Eric Brunner, Michael Marmot
International Centre for Health and Society, Department of Epidemiology and Public Health, University College London Medical School, 1-19 Torrington Place, London WC1E 6BT

H Hemingway M Shipley

S Stansfeld

E Brunner

M Marmot

Department of Research and Development, Kensington and Chelsea and Westminster Health Authority, London H Hemingway

Department of Clinical Epidemiology and

Biostatistics, McMaster University, Hamilton, Ontario,

Canada

H Shannon

Institute for Work and Health, Toronto, Canada

H Shannon

J Frank

Correspondence to: Dr H Hemingway.

Accepted for publication 15 June 1998

\section{Abstract}

Study objective-To explore the previously stated hypothesis that risk factors for atherothrombotic disease are associated with back pain.

Design-Prospective (mean of four years of follow up) and retrospective analyses using two main outcome measures: (a) short ( $\leqslant 7$ days) and long ( $>7$ days) spells of sickness absence because of back pain reported separately in men and women; (b) consistency of effect across the resulting four duration of spell and sex cells. Setting-14 civil service departments in London

Participants-3506 male and 1380 female white office-based civil servants, aged 35-55 years at baseline.

Main results-In age adjusted models, low apo AI was associated with back pain across all four duration-sex cells and smoking was associated across three cells. Six factors were associated with back pain in two cells: low exercise and high BMI, waist-hip ratio, triglycerides, insulin and Lp(a). On full adjustment (for age, BMI, employment grade and back pain at baseline), each of these factors retained a statistically significant effect in at least one duration-sex cell. Triglycerides were associated with short and long spells of sickness absence because of back pain in men in fully adjusted models with rate ratios $(95 \%$ confidence intervals) of 1.53 $(1.1,2.1)$ and $1.75(1.0,3.2)$ respectively. There was little or no evidence of association in age adjusted models with: fibrinogen, glucose tolerance, total cholesterol, apoB, hypertension, factor VII, von Willebrand factor, electrocardiographic evidence of coronary heart disease and reported angina.

Conclusions-In this population of office workers, only modest support was found for an atherothrombotic component to back pain sickness absence. However, the young age of participants at baseline and the lack of distinction between different types of back pain are likely to bias the findings toward null. Further research is required to ascertain whether a population sub-group of atherothrombotic back pain can be identified.

(F Epidemiol Community Health 1999;53:197-203)
Despite an epidemic of disability because of back pain, the aetiology remains poorly understood. ${ }^{1}$ For decades, a pathophysiological model of back pain that emphasises trauma and soft tissue injury has been dominant and population studies have therefore concentrated on physical risk factors (such as lifting, twisting, and bending) in manual occupations. ${ }^{2}$ However, even with improved methods of measurement, much back pain cannot be attributed to such physical exposures ${ }^{3}$ and the majority of people with back pain have no intervertebral disc lesion. ${ }^{45}$ More recently evidence from pathological, biochemical, and epidemiological studies have led to the hypothesis that atherothrombotic disease of the lumbar arteries may play an aetiological part in back pain. ${ }^{6}$

Each vertebral segment from the upper thoracic to the fourth lumbar receives a pair of arteries from the posterior wall of the aorta. ${ }^{6}$ Angiographic studies determining the extent of atheromatous stenoses in the lumbar arteries have demonstrated associations between the extent of atherosclerosis and stage of disc degeneration on anteroposterior and lateral radiographs. ${ }^{7}$ In a necropsy study, subjects who had a history of back pain of at least three months duration had more occluded and narrowed lumbar and middle sacral arteries than had controls of the same age group. ${ }^{8}$ Altered vascular perfusion has been found in patients with sciatica and low back pain. ${ }^{9}$ Among patients with chronic back pain, a defect in fibrinolysis has been found in some studies $^{10}$ and it has been proposed that fibrin deposition and scar formation could be responsible for the development, or the perpetuation, of chronic inflammation at sites of damage in the spine.

Epidemiological studies have identified some overlap in the behavioural risk factors for back pain and for cardiovascular disease. Smoking and obesity have been found in some studies to predict back pain. ${ }^{11-15}$ Furthermore, it has been reported that among men aged 30-49 years, those reporting back pain have an increased risk specifically of ischaemic heart disease mortality, ${ }^{16}$ although this is not a consistent finding. ${ }^{17}$ More recently calcific findings in the posterior wall of the abdominal aorta were found to predict disc degeneration and the occurrence of back pain over a 25 year follow up period. ${ }^{18}$

However, no previous epidemiological studies have investigated the extent to which a 
comprehensive range of biological as well as behavioural risk factors predict back pain in a working population. In such a population, sickness absence because of back pain represents a measure of functional disability and public health impact. The Whitehall II study of British civil servants is uniquely able to investigate these issues in a cohort of office workers. The objective therefore of this investigation was to measure the extent to which the same behavioural and biological factors that are known to predict the risk of atherothrombotic arterial disease in coronary, carotid and peripheral circulations also predict spells of sickness absence because of back pain.

\section{Methods}

STUDY POPULATION

All non-industrial civil servants aged 35-55 working in the London offices of 20 departments were invited to participate in the study. The overall response rate was $73 \%$, although the true response rate is likely to be higher because around $4 \%$ of those on the list of employees had in fact moved before the study and were thus not eligible for inclusion. In total, 10308 civil servants participated of whom 67\% (6894) were men and 33\% (3414) were women. Details of the validity and reliability of the questionnaire, clinical and biochemical measurements in the Whitehall II study are given elsewhere. ${ }^{19} 20$

ATHEROTHROMBOTIC RISK FACTORS MEASURED AT BASELINE (1985-1988)

Between November 1985 and March 1988 participants completed a questionnaire and attended a screening examination (phase 1, baseline). The questionnaire included details on current civil service employment grade (divided into six levels), which was used as a measure of socioeconomic status. Smoking was categorised (never, ex and current) and quantified by packyears based on responses at phase 1. Leisure time physical activity was categorised as vigorous (one hour or more of vigorous activity, such as running or digging, per week), moderate (less than one hour of vigorous activity and one hour or more of moderately energetic activity, such as scrubbing or polishing car) mild (less than one hour of moderate activity) or none. Alcohol intake was assessed by the number of units of alcohol consumed in the last week.

Prevalent coronary heart disease at phase 1 was defined by Rose angina questionnaire, ${ }^{21}$ self report of doctor diagnosed heart attack or angina $(n=150)$, probable or possible ischaemia on resting electrocardiogram (Minnesota codes $1-1$ to $1-3,4-1$ to $4-4,5-1$ to $5-3$ and $7-1-1)$. Intermittent claudication was defined by questionnaire. ${ }^{21}$ Blood pressure was measured twice in the sitting position after five minutes rest with the Hawksley random-zero sphygmomanometer. Hypertension was defined as systolic blood pressure $\geqslant 160 \mathrm{~mm} \mathrm{Hg}$ or diastolic blood pressure $\geqslant 90 \mathrm{~mm} \mathrm{Hg}$, or treatment with anti-hypertensive medication. Height and weight were measured at phase 1, and body mass index (BMI) was calculated as weight $(\mathrm{kg}) /$ height $\left(\mathrm{m}^{2}\right)$.

Cholesterol concentration was determined by the cholesterol oxidase-peroxidase colorimetric method (Boehringer Mannheim kit). Apo AI and apo B were determined by an immunoturbimetric method. ${ }^{22}$ HDL cholesterol was determined after dextran sulphatemagnesium chloride precipitation of non-HDL cholesterol. LDL cholesterol was derived from the Friedewald equation. ${ }^{23}$

ATHEROTHROMBOTIC RISK FACTORS MEASURED AT PHASE 3 FOLLOW UP (1991-1993)

A total of $8355(83 \%)$ of participants at baseline took part in the third phase of data collection, full details of which have been described elsewhere. ${ }^{24}$ The following risk factor measurements were added in the whole cohort at phase 3: waist hip ratio, $\mathrm{Lp}(\mathrm{a})$, trigylcerides, glucose tolerance, insulin, fibrinogen, factor VII, von Willebrand factor. Waist circumference (smallest circumference at or below the costal margin) and hip circumference (at the level of the greater trochanter of the right femur) were recorded with subjects in the standing position, unclothed using a fibreglass tape measure at $600 \mathrm{~g}$ tension. Waist-hip ratio was calculated as the ratio of the two circumference measurements. Glucose tolerance was defined as normal, impaired or diabetic on the basis of a $75 \mathrm{~g}$ oral glucose tolerance test. ${ }^{25}$ Treated diabetics were assigned to the diabetic category. The following methods were used for the biochemical analytes at phase 3: lipoprotein (a) (immunoturbidimetric ${ }^{22}$ ), triglycerides (enzymatic colorimetric), glucose (electrochemical glucose oxidase), insulin (radioimmunoassay using polyclonal guinea pig antiserum), fibrinogen (modification of the clotting method of Clauss ${ }^{26}$ ), factor VII activity (Brozovic method ${ }^{27}$ ) von Willebrand factor (double antibody ELISA). People were considered to have the metabolic syndrome when three or more of the following were in the adverse quintile: two hour glucose, systolic blood pressure, fasting triglycerides, HDL cholesterol, waist-hip ratio. ${ }^{28}$

BACK PAIN OUTCOMES: SICKNESS ABSENCE

(1985-1990)

Most participants (94\%) gave consent for follow up based on their sickness absence records. These records included the first and last dates of all absences from entry into the study until the end of 1990. Therefore measurement of risk factors at phase 3 took place after the end of follow up for spells of back pain sickness absence. Of the 20 civil service departments participating in the Whitehall II study, 14 coded the reason for the absence. For absences of seven days or fewer ("short spells"), civil servants were able to complete their own certificate explaining their absence. For absences of more than seven calendar days ("long spells"), a medical certificate from the general practitioner (GP) was required. As ethnicity is strongly related to both sickness absence because of back pain and many of the atherothrombotic risk factors, ${ }^{29}$ all 
Table 1 Age adjusted rate ratios (95\% confidence intervals) for sickness absence because of back pain by atherothrombotic risk factors measured at baseline

\begin{tabular}{|c|c|c|c|c|}
\hline & \multicolumn{2}{|l|}{$\operatorname{Men}(n=3506)$} & \multicolumn{2}{|l|}{ Women $(n=1380)$} \\
\hline & Short spells $\leqslant 7$ days & Long spells $>7$ days & Short spells $\leqslant 7$ days & Long spells $>7$ days \\
\hline Number of spells & 398 & 113 & 197 & 70 \\
\hline Rate $^{\star}$ per 100 person years & 3.39 & 0.94 & 4.15 & 1.45 \\
\hline \multicolumn{5}{|l|}{ Height (tertiles) } \\
\hline low & 1.0 & 1.0 & 1.0 & 1.0 \\
\hline med & $0.68(0.5,0.9)$ & $1.05(0.6,1.7)$ & $0.99(0.7,1.4)$ & $1.05(0.6,1.9)$ \\
\hline high & $0.98(0.8,1.2)$ & $1.39(0.9,2.2)$ & $1.04(0.7,1.5)$ & $1.02(0.6,1.8)$ \\
\hline \multicolumn{5}{|l|}{ Body mass index $\left(\mathrm{kg} / \mathrm{m}^{2}\right)$} \\
\hline$<20$ & 1.0 & 1.0 & 1.0 & - \\
\hline $20-24.9$ & $1.06(0.6,1.8)$ & $0.75(0.3,1.9)$ & $1.87(0.9,3.8)$ & 1.0 \\
\hline $25-29.9$ & $1.23(0.7,2.1)$ & $1.27(0.5,3.2)$ & $2.51(1.2,5.2)$ & $1.54(0.9,2.6)$ \\
\hline$\geqslant 30$ & $0.74(0.3,1.6)$ & $1.66(0.5,5.0)$ & $2.40(1.9,5.4)$ & $0.98(0.4,2.2)$ \\
\hline \multicolumn{5}{|l|}{ Exercise } \\
\hline vigorous & 1.0 & 1.0 & 1.0 & 1.0 \\
\hline moderate & $1.01(0.8,1.2)$ & $0.89(0.6,1.3)$ & $1.39(0.9,2.1)$ & $0.80(0.4,1.5)$ \\
\hline none/mild & $1.35(1.0,1.8)$ & $1.56(0.9,2.7)$ & $1.85(1.2,2.8)$ & $1.08(0.6,2.1)$ \\
\hline \multicolumn{5}{|l|}{ Smoking (pack years) } \\
\hline Never & 1.0 & 1.0 & 1.0 & 1.0 \\
\hline Ex & $1.13(0.9,1.4)$ & $0.91(0.6,1.4)$ & $1.65(1.2,2.3)$ & $0.95(0.5,1.8)$ \\
\hline \multicolumn{5}{|l|}{ Current } \\
\hline$<15$ pyrs & $0.53(0.3,1.0)$ & $0.52(0.2,1.7)$ & $0.71(0.3,1.6)$ & $0.88(0.3,2.9)$ \\
\hline $15-29$ pyrs & $0.73(0.4,1.3)$ & $0.96(0.4,12.2)$ & $1.79(1.2,2.8)$ & $2.22(1.2,4.2)$ \\
\hline$\geqslant 30$ pyrs & $1.84(1.3,2.7)$ & $1.93(0.9,3.9)$ & $2.41(1.5,3.9)$ & $1.56(0.7,3.6)$ \\
\hline \multicolumn{5}{|l|}{ Alcohol (units/week) } \\
\hline 0 & 1.0 & 1.0 & 1.0 & 1.0 \\
\hline $1-14$ & $1.66(1.1,2.5)$ & $0.90(0.5,1.6)$ & $1.00(0.7,1.4)$ & $0.62(0.4,1.0)$ \\
\hline $15-21$ & $1.91(1.2,3.1)$ & $0.62(0.3,1.5)$ & $0.92(0.4,1.2)$ & $0.25(0.1,0.8)$ \\
\hline $22+$ & $1.89(1.2,2.9)$ & $1.13(0.6,2.2)$ & & \\
\hline \multicolumn{5}{|l|}{ Total cholesterol } \\
\hline low & 1.0 & 1.0 & 1.0 & 1.0 \\
\hline med & $1.12(0.9,1.4)$ & $1.09(0.7,1.7)$ & $0.94(0.6,1.4)$ & $1.52(0.8,2.9)$ \\
\hline high & $0.92(0.7,1.2)$ & $1.17(0.7,1.9)$ & $1.12(0.8,1.6)$ & $1.20(0.6,2.4)$ \\
\hline \multicolumn{5}{|l|}{ Apo AI } \\
\hline high & 1.0 & 1.0 & 1.0 & 1.0 \\
\hline med & $1.30(1.0,1.7)$ & $1.59(1.0,2.6)$ & $1.10(0.7,1.6)$ & $1.37(0.7,2.8)$ \\
\hline low & $1.22(0.9,1.6)$ & $1.36(0.8,2.3)$ & $1.68(1.2,2.4)$ & $2.60(1.4,5.0)$ \\
\hline \multicolumn{5}{|l|}{ HDL cholesterol } \\
\hline high & 1.0 & 1.0 & 1.0 & 1.0 \\
\hline med & $1.13(0.9,1.5)$ & $1.15(0.7,2.0)$ & $1.57(1.0,2.4)$ & $2.16(1.0,4.7)$ \\
\hline low & $1.13(0.9,1.5)$ & $1.78(1.1,3.0)$ & $1.56(1.0,2.4)$ & $2.40(1.1,5.2)$ \\
\hline \multicolumn{5}{|l|}{ Apo B } \\
\hline low & 1.0 & 1.0 & 1.0 & 1.0 \\
\hline med & $1.06(0.8,1.4)$ & $1.11(0.7,1.8)$ & $1.19(0.8,1.8)$ & $1.13(0.6,2.2)$ \\
\hline high & $0.96(0.7,1.3)$ & $1.24(0.8,2.0)$ & $1.37(0.9,2.0)$ & $1.11(0.6,2.2)$ \\
\hline \multicolumn{5}{|l|}{ LDL cholesterol } \\
\hline low & 1.0 & 1.0 & 1.0 & 1.0 \\
\hline med & $0.77(0.6,1.0)$ & $0.62(0.4,1.1)$ & $1.03(0.7,1.6)$ & $1.55(0.7,3.3)$ \\
\hline high & $0.93(0.7,1.2)$ & $1.05(0.7,1.7)$ & $1.34(0.9,2.0)$ & $1.23(0.5,2.8)$ \\
\hline \multicolumn{5}{|l|}{ Hypertension } \\
\hline no & 1.0 & 1.0 & 1.0 & \\
\hline yes & $1.07(0.7,1.6)$ & $1.45(0.7,2.9)$ & $1.49(0.8,2.6)$ & $t$ \\
\hline \multicolumn{5}{|l|}{ ECG ischaemia } \\
\hline no & 1.0 & 1.0 & 1.0 & 1.0 \\
\hline yes & $1.12(0.7,1.7)$ & $0.85(0.3,2.1)$ & $1.27(0.8,2.1)$ & $1.01(0.4,2.5)$ \\
\hline \multicolumn{5}{|l|}{ Rose angina } \\
\hline no & 1.0 & 1.0 & 1.0 & 1.0 \\
\hline yes & $0.70(0.3,1.6)$ & $1.08(0.3,3.4)$ & $0.74(0.3,1.6)$ & $0.78(0.2,3.2)$ \\
\hline Menopausal status & & & & \\
\hline pre & - & - & 1.0 & 1.0 \\
\hline post & & & $1.35(0.9,2.0)$ & $1.70(0.9,3.2)$ \\
\hline
\end{tabular}

${ }^{\star}$ Overall rate is adjusted for age. †Only one event.

analyses were carried out in a white population only ( $n=3506$ men and $n=1380$ women).

The reasons for absence were coded by the civil service based on the 8th revision of the International Classification of Diseases. All codes relating to back pain were included: disc intervertebral (displaced, lesion, prolapsed, slipped), disc pain, sciatica, pain legs, back pain, backache, pain low back (muscular, rheumatic), lumbago, lumbar strain. A comparison of stated reasons for absence and the diagnosis of the GP in spells lasting more than 21 days, showed disagreement in 12 of 65 participants where the GP provided only one reason for absence and disagreement in 1 of 20 where the GP provided more than one reason for absence.
The validity of the sickness absence because of back pain is further supported by the relation with self reported back pain at baseline. The baseline questionnaire included three questions on back pain: in the past 14 days, in the past 12 months and as a longstanding illness. ${ }^{30}$ The number of self reports of back pain at baseline (maximum of three) was strongly related to subsequent sickness absence because of back pain (but not other reasons) on follow up ${ }^{31}$; for short spells the effect of 1, 2 and 3 reports of back pain compared with none was associated with age adjusted rate ratios ( $95 \%$ confidence intervals) of $2.26(1.8,2.9), 3.74(3.0,4.7)$, and 7.16 $(5.4,9.4)$ respectively. For long spells the 
Table 2 Age adjusted rate ratios (95\% confidence intervals) for sickness absence because of back pain by atherothrombotic risk factors measured at phase 3

\begin{tabular}{|c|c|c|c|c|}
\hline & \multicolumn{2}{|l|}{ Men } & \multicolumn{2}{|l|}{ Women } \\
\hline & $\begin{array}{l}\text { Short spell } \leqslant 7 \\
\text { days }\end{array}$ & $\begin{array}{l}\text { Long spells }>7 \\
\text { days }\end{array}$ & $\begin{array}{l}\text { Short spells } \leqslant 7 \\
\text { days }\end{array}$ & $\begin{array}{l}\text { Long spells }>7 \\
\text { days }\end{array}$ \\
\hline \multicolumn{5}{|c|}{ Waist-hip ratio (tertiles) } \\
\hline low & 1.0 & 1.0 & 1.0 & 1.0 \\
\hline med & $1.25(0.9,1.7)$ & $1.31(0.7,2.3)$ & $1.20(0.8,1.9)$ & $1.96(0.9,4.2)$ \\
\hline high & $1.18(0.9,1.6)$ & $1.93(1.1,3.3)$ & $1.76(1.1,2.7)$ & $1.48(0.6,3.4)$ \\
\hline \multicolumn{5}{|c|}{ Lipoprotein (a) } \\
\hline low & 1.0 & 1.0 & 1.0 & 1.0 \\
\hline med & $0.99(0.7,1.3)$ & $0.77(0.5,1.3)$ & $0.93(0.6,1.4)$ & $2.12(1.0,4.5)$ \\
\hline high & $1.47(1.1,1.9)$ & $0.70(0.4,1.2)$ & $1.14(0.8,1.7)$ & $1.68(0.7,3.8)$ \\
\hline \multicolumn{5}{|l|}{ Triglycerides } \\
\hline low & 1.00 & 1.00 & 1.00 & 1.0 \\
\hline med & $1.18(0.9,1.6)$ & $1.42(0.8,2.5)$ & $1.14(0.8,1.7)$ & $0.86(0.4,1.8)$ \\
\hline high & $1.53(1.2,2.0)$ & $2.24(1.3,3.8)$ & $1.36(0.9,2.1)$ & $1.01(0.5,2.1)$ \\
\hline \multicolumn{5}{|c|}{ Glucose tolerance } \\
\hline normal & 1.0 & 1.0 & 1.0 & 1.0 \\
\hline impaired & $1.31(0.9,2.0)$ & $1.42(0.7,3.1)$ & $0.48(0.2,1.1)$ & $1.48(0.6,3.5)$ \\
\hline diabetic & $1.16(0.5,2.5)$ & $2.03(0.6,6.5)$ & $1.79(0.7,4.4)$ & $1.18(0.2,8.6)$ \\
\hline \multicolumn{5}{|l|}{ Insulin } \\
\hline low & 1.0 & 1.0 & 1.0 & 1.0 \\
\hline med & $1.33(1.0,1.8)$ & $1.07(0.6,1.8)$ & $1.52(1.1,2.3)$ & $1.23(0.6,2.6)$ \\
\hline high & $1.40(1.0,1.9)$ & $1.23(0.8,2.2)$ & $1.17(0.8,1.8)$ & $1.27(0.6,2.7)$ \\
\hline \multicolumn{5}{|c|}{ Metabolic syndrome } \\
\hline no & 1.0 & 1.0 & 1.0 & 1.0 \\
\hline yes & $0.89(0.6,1.3)$ & $2.34(1.4,3.9)$ & $1.48(0.9,2.3)$ & $1.27(0.6,2.9)$ \\
\hline \multicolumn{5}{|l|}{ Fibrinogen } \\
\hline low & 1.0 & 1.0 & 1.0 & 1.0 \\
\hline med & $1.34(1.0,1.8)$ & $0.92(0.5,1.6)$ & $1.07(0.7,1.6)$ & $2.11(0.9,4.7)$ \\
\hline high & $1.43(1.0,2.0)$ & $1.04(0.6,1.8)$ & $1.25(0.8,1.9)$ & $2.01(0.9,4.6)$ \\
\hline \multicolumn{5}{|l|}{ Factor VII } \\
\hline low & 1.0 & 1.0 & 1.0 & 1.0 \\
\hline med & $1.08(0.8,1.4)$ & $1.01(0.6,1.7)$ & $1.07(0.7,1.7)$ & $1.10(0.5,2.4)$ \\
\hline high & $0.93(0.7,1.3)$ & $0.85(0.5,1.5)$ & $1.29(0.8,2.0)$ & $1.19(0.5,2.6)$ \\
\hline \multicolumn{5}{|c|}{ von Willebrand factor } \\
\hline low & 1.0 & 1.0 & 1.0 & 1.0 \\
\hline med & $0.80(0.6,1.1)$ & $0.77(0.5,1.3)$ & $0.70(0.5,1.1)$ & $0.92(0.4,2.0)$ \\
\hline high & $0.95(0.7,1.3)$ & $0.96(0.6,1.6)$ & $0.48(0.3,0.8)$ & $1.02(0.5,2.2)$ \\
\hline
\end{tabular}

corresponding rate ratios were $1.57(0.9,2.6)$, $3.36(2.2,5.3)$, and $3.94(2.0,7.7)$ respectively.

\section{STATISTICAL ANALYSIS}

Continuous exposures were divided into sex specific tertiles, with the a priori lowest risk category taken as reference. For each employee, the number of spells of sickness absence of each type was computed and the follow up period was measured in person years. Rates of sickness absence were expressed per 100 person years. Age adjusted rates were calculated by direct standardisation using the total study population as the standard. The number of spells of sickness absence is a form of count data and therefore Poisson regression models were used to calculate adjusted rate ratios and their $95 \%$ confidence intervals. Details of the method used have been reported previously. ${ }^{32}$ Analyses of sickness absence rates were carried out using the statistical software SAS (SAS, Cary, NC) and the Poisson regression models were fitted using EGRET.

Short spells ( $\leqslant 7$ days) and long spells ( $>7$ days) of sickness absence were analysed separately in men and women-yielding four rate ratios for each putative risk factor. Consistency of effect was indicated by the number of these duration-sex cells $(0-4)$ in which the confidence intervals for any of the rate ratios did not span unity and in which the direction of effect was the same as in established atherothrombotic disorders. The duration of spells of back pain absence gives a measure of functional severity. Twenty three per cent of all spells of sickness absence because of back pain were recurrent. The importance of considering women separately from men (rather than adjusting for sex) in aetiological studies of atherothrombotic diseases has been emphasised. ${ }^{33}$

Many of the above risk factors are intercorrelated and are measured with differing precision. Confounder adjustments in this situation may give spurious results. ${ }^{34}$ Furthermore the prior aim of the analyses was to explore possible risk factor relations with a large number of exposures, rather than to test the independence of a single exposure. For these reasons statistical modelling was governed by an a priorirather than a statistical-choice of potential confounders. Only those factors that showed an effect in two or more duration-sex cells in age adjusted models were then further adjusted in two models. (a) Age + BMI adjusted models were carried out to investigate the possibility that people with back pain may take less exercise with consequent rise in BMI, followed by disturbances in lipid and carbohydrate metabolism. (b) Further adjustment for the potential confounding of employment grade and baseline back pain was made in a second model. Employment grade is strongly related to sickness absence because of back pain ${ }^{31}$ and to many of the exposures. ${ }^{192028}$

\section{Results}

AGE ADJUSTED ANALYSES

Over a mean four year follow up period from baseline, there were 398 short spells and 113 long spells in men and 197 and 70 respectively in women. The age adjusted rate ratios for short and long spells of sickness absence because of back pain are shown in table 1 for risk factors measured at baseline and in table 2 for risk factors measured at phase 3 . Results are described below in order of consistency of effect.

The most consistent effect was observed for apo AI, with medium/low values being associated in all four duration-sex cells with higher rate ratios of sickness absence because of back pain. For example, in the women this was statistically significant with the age adjusted rate ratios (comparing low versus high tertile) being $1.68(1.2,2.4)$ for short spells and 2.60 (1.4, 5.0) for long spells.

Compared with never smokers, current smokers had increased risk of sickness absence because of back pain. However, the risk among current smokers was confined to those with $\geqslant 15$ pack years (women) and $\geqslant 30$ pack years for men.

Six factors were associated with back pain in two of the duration-sex cells: low exercise and high BMI, waist-hip ratio, triglycerides, insulin and $\mathrm{Lp}(\mathrm{a})$. For triglycerides in men the rate ratios comparing high versus low tertiles were $1.53(1.2,2.0)$ and $2.24(1.3,3.8)$ for short and long spells respectively. For insulin, the rate ratios for the medium and high tertiles were all greater than one significantly so for the effect on short spells in the high tertile in men (rate ratio $1.40(1.0,1.9)$ ) and for women for the medium tertile only $(1.52(1.0,2.1))$ For 
Table 3 Adjusted rate ratios (95\% confidence intervals) for short and long spells of sickness absence because of back pain in men

\begin{tabular}{|c|c|c|c|c|}
\hline & \multicolumn{2}{|c|}{ Short spells $\leqslant 7$ days } & \multicolumn{2}{|c|}{ Long spells $>7$ days } \\
\hline & $\begin{array}{l}\text { Age and BMI } \\
\text { adjusted }\end{array}$ & $\begin{array}{l}\text { Age }+ \text { BMI }+ \\
\text { grade }+ \text { baseline } \\
\text { back pain }\end{array}$ & $\begin{array}{l}\text { Age and BMI } \\
\text { adjusted }\end{array}$ & $\begin{array}{l}\text { Age }+ \text { BMI }+ \\
\text { grade }+ \text { baseline } \\
\text { back pain }\end{array}$ \\
\hline \multicolumn{5}{|l|}{ Apo AI } \\
\hline high & 1.0 & 1.0 & 1.0 & 1.0 \\
\hline med & $1.40(1.0,1.9)$ & $1.13(0.8,1.5)$ & $1.59(0.9,2.7)$ & $1.40(0.8,2.4)$ \\
\hline low & $1.30(1.0,1.8)$ & $1.03(0.8,1.4)$ & $1.08(0.6,2.0)$ & $0.92(0.5,1.7)$ \\
\hline \multicolumn{5}{|c|}{ Smoking (pack years) } \\
\hline Never & 1.0 & 1.0 & 1.0 & 1.0 \\
\hline $\mathrm{Ex}$ & $1.13(0.9,1.4)$ & $1.03(0.8,1.3)$ & $0.86(0.5,1.4)$ & $0.84(0.5,1.3)$ \\
\hline \multicolumn{5}{|l|}{ Current } \\
\hline$<15$ pyrs & $0.51(0.3,1.0)$ & $0.45(0.2,0.9)$ & $0.63(0.2,2.0)$ & $0.59(0.2,1.9)$ \\
\hline $15-29$ pyrs & $0.49(0.3,1.0)$ & $0.36(0.2,0.7)$ & $0.70(0.3,2.0)$ & $0.59(0.2,1.7)$ \\
\hline$\geqslant 30$ pyrs & $1.92(1.3,2.9)$ & $1.09(0.7,1.6)$ & $2.31(1.1,4.7)$ & $1.72(0.8,3.6)$ \\
\hline \multicolumn{5}{|l|}{ Exercise } \\
\hline vigorous & 1.0 & 1.0 & 1.0 & 1.0 \\
\hline moderate & $1.01(0.8,1.3)$ & $0.96(0.8,1.2)$ & $0.76(0.5,1.2)$ & $0.75(0.5,1.2)$ \\
\hline none/mild & $1.26(0.9,1.8)$ & $0.85(0.6,1.2)$ & $1.44(0.8,2.6)$ & $1.17(0.6,2.2)$ \\
\hline \multicolumn{5}{|c|}{ Waist-hip ratio (tertiles) ${ }^{\star}$} \\
\hline low & 1.0 & 1.0 & 1.0 & 1.0 \\
\hline med & $1.14(0.8,1.6)$ & $1.06(0.8,1.4)$ & $0.98(0.5,1.9)$ & $0.97(0.5,1.8)$ \\
\hline high & $1.21(0.9,1.7)$ & $1.06(0.8,1.5)$ & $1.44(0.8,2.8)$ & $1.34(0.7,2.6)$ \\
\hline \multicolumn{5}{|l|}{ Lipoprotein $(a)^{\star}$} \\
\hline low & 1.0 & 1.0 & 1.0 & 1.0 \\
\hline med & $1.05(0.8,1.4)$ & $1.01(0.7,1.4)$ & $0.58(0.3,1.0)$ & $0.56(0.3,1.0)$ \\
\hline high & $1.50(1.1,2.0)$ & $1.39(1.0,1.9)$ & $0.69(0.4,1.2)$ & $0.67(0.4,1.1)$ \\
\hline \multicolumn{5}{|l|}{ Triglycerides* } \\
\hline low & 1.0 & 1.0 & 1.0 & 1.0 \\
\hline med & $1.23(0.9,1.7)$ & $1.19(0.9,1.6)$ & $1.17(0.6,2.2)$ & $1.12(0.6,2.1)$ \\
\hline high & $1.58(1.2,2.2)$ & $1.53(1.1,2.1)$ & $1.82(1.0,3.3)$ & $1.75(1.0,3.2)$ \\
\hline \multicolumn{5}{|l|}{ Insulin $\star$} \\
\hline low & 1.0 & 1.0 & 1.0 & 1.0 \\
\hline med & $1.31(1.0,1.8)$ & $1.34(1.0,1.9)$ & $1.06(0.6,1.9)$ & $1.13(0.6,2.0)$ \\
\hline high & $1.48(1.1,2.0)$ & $1.37(1.0,1.9)$ & $1.04(0.6,1.9)$ & $1.06(0.6,1.9)$ \\
\hline
\end{tabular}

^Phase 3 measurement.

Table 4 Adjusted rate ratios (95\% confidence intervals) for short and long spells of sickness absence because of back pain in women

\begin{tabular}{|c|c|c|c|c|}
\hline & \multicolumn{2}{|c|}{ Short spells $\leqslant 7$ days } & \multicolumn{2}{|c|}{ Long spells $>7$ days } \\
\hline & $\begin{array}{l}\text { Age and BMI } \\
\text { adjusted }\end{array}$ & $\begin{array}{l}\text { Age }+ \text { BMI }+ \\
\text { grade }+ \text { baseline } \\
\text { back pain }\end{array}$ & $\begin{array}{l}\text { Age and BMI } \\
\text { adjusted }\end{array}$ & $\begin{array}{l}\text { Age }+ \text { BMI+ } \\
\text { grade }+ \text { baseline } \\
\text { back pain }\end{array}$ \\
\hline \multicolumn{5}{|l|}{ Apo AI } \\
\hline high & 1.0 & 1.0 & 1.0 & 1.0 \\
\hline med & $1.16(0.7,1.8)$ & $1.10(0.7,1.7)$ & $1.64(0.7,3.8)$ & $1.54(0.7,3.6)$ \\
\hline low & $1.54(1.0,2.4)$ & $1.53(1.0,2.4)$ & $1.90(0.8,4.5)$ & $2.00(0.8,4.8)$ \\
\hline \multicolumn{5}{|c|}{ Smoking (pack years) } \\
\hline Never & 1.0 & 1.0 & 1.0 & 1.0 \\
\hline Ex & $1.70(1.2,2.5)$ & $1.66(1.1,2.5)$ & $0.91(0.4,1.9)$ & $0.87(0.4,1.8)$ \\
\hline \multicolumn{5}{|l|}{ Current } \\
\hline$<15$ pyrs & $0.65(0.2,1.8)$ & $0.58(0.2,1.6)$ & $0.92(0.2,3.9)$ & $0.89(0.2,3.9)$ \\
\hline $15-29$ pyrs & $1.80(1.0,2.6)$ & $1.46(0.9,2.4)$ & $1.92(0.9,4.1)$ & $1.75(0.8,3.8)$ \\
\hline$\geqslant 30$ pyrs & $2.48(1.4,4.3)$ & $2.20(1.3,3.8)$ & $1.66(0.6,4.5)$ & $1.28(0.5,3.6)$ \\
\hline \multicolumn{5}{|l|}{ Exercise } \\
\hline vigorous & 1.0 & 1.0 & 1.0 & 1.0 \\
\hline moderate & $1.64(1.0,2.6)$ & $1.61(1.0,2.6)$ & $0.68(0.3,1.4)$ & $0.68(0.3,1.4)$ \\
\hline none/mild & $2.04(1.2,3.4)$ & $1.76(1.1,2.9)$ & $1.19(0.6,2.5)$ & $1.01(0.5,2.2)$ \\
\hline \multicolumn{5}{|c|}{ Waist-hip ratio (tertiles)^ } \\
\hline low & 1.0 & 1.0 & 1.0 & 1.0 \\
\hline med & $1.05(0.6,1.7)$ & $1.10(0.7,1.8)$ & $0.84(0.3,2.2)$ & $0.80(0.3,2.2)$ \\
\hline high & $1.91(1.1,3.3)$ & $1.87(1.1,3.2)$ & $1.03(0.3,3.1)$ & $0.82(0.3,2.5)$ \\
\hline \multicolumn{5}{|l|}{ Lipoprotein $(a)^{\star}$} \\
\hline low & 1.0 & 1.0 & 1.0 & 1.0 \\
\hline med & $0.96(0.6,1.5)$ & $0.95(0.6,1.5)$ & $3.77(1.3,11.4)$ & $3.29(1.1,10.1)$ \\
\hline high & $1.20(0.8,1.9)$ & $1.17(0.7,1.9)$ & $2.57(0.8,8.4)$ & $2.38(0.7,7.9)$ \\
\hline \multicolumn{5}{|l|}{ Triglycerides ${ }^{\star}$} \\
\hline low & 1.0 & 1.0 & 1.0 & 1.0 \\
\hline med & $1.07(0.7,1.7)$ & $1.18(0.7,1.9)$ & $0.74(0.3,1.8)$ & $0.80(0.3,2.0)$ \\
\hline & $1.33(0.8,2.2)$ & $1.47(0.9,2.5)$ & $0.68(0.3,1.8)$ & $0.76(0.3,2.1)$ \\
\hline \multicolumn{5}{|l|}{ Insulin $\star$} \\
\hline low & 1.0 & 1.0 & 1.0 & 1.0 \\
\hline med & $1.55(1.0,2.5)$ & $1.76(1.1,2.8)$ & $1.02(0.4,2.9)$ & $1.07(0.4,3.0)$ \\
\hline high & $1.07(0.6,1.8)$ & $1.22(0.7,2.1)$ & $1.25(0.5,3.4)$ & $1.36(0.5,3.8)$ \\
\hline
\end{tabular}

^Phase 3 measurement.

lipoprotein (a) the effect was found for short spells in men and for long spells in women.

Fibrinogen showed an effect in only one cell-for short spells in men (rate ratio 1.43 $(1.0,2.0)$ - -although the effect for long spells in women was of borderline significance in both the medium and high tertiles with rate ratios of 2.11 and 2.01 respectively.

There was little or no evidence of association in the hypothesised direction in any of the duration-sex cells for the following: total cholesterol, apoB, hypertension, factor VII, von Willebrand factor, electrocardiographic evidence of coronary artery disease and reported angina. There were a maximum of two spells of absence among those with intermittent claudication and therefore the rate ratios were not calculated. In men for short spells, heavy alcohol consumption (>21 units per week) showed a direct association but in women heavy consumption ( $>14$ units per week) showed an inverse association.

\section{MULTIVARIATE ANALYSES}

The seven risk factors other than BMI showing associations in two or more duration-sex cells were then adjusted for (a) age +BMI and (b) age $+\mathrm{BMI}+$ employment grade + baseline back pain ("full adjustment"). The results are shown in table 3 (men) and table (women). On full adjustment, each factor retained a statistically significant effect in at least one durationsex cell. For long spells, because of small numbers, none of the risk factors showed significant associations on full adjustment with the exception of triglycerides in men and $\operatorname{Lp}(\mathrm{a})$ in women. For short spells there was a different pattern of association between men and women. For short spells in women, unlike men, the effect of apo AI, smoking, exercise and waist hip ratio all persisted on full adjustment. Triglycerides were associated with short and long spells of sickness absence because of back pain in men in fully adjusted models with rate ratios of $1.53(1.1,2.1)$ and $1.75(1.0,3.2)$ respectively. For short spells in women, the corresponding rate ratio was $1.47(0.9,2.5)$. $\mathrm{Lp}(\mathrm{a})$ and insulin and were associated with short spells in men with rate ratios of (1.39 $(1.0,1.9)$ and $1.37(1.0,1.9)$ respectively.

Adjusting the effect of BMI for age + grade + back pain at baseline gave rate ratios of 1.0, $1.35(0.8,2.4), 1.46((0.8,2.6)$ and $0.87(0.4$, 1.9) for short spells in men (the exposure groups are as those in table 1). The corresponding rate ratios were $1.0,1.91(0.8,4.7)$, $2.22(0.9,5.6)$ and $2.02(0.7,5.6)$ in women.

\section{Discussion}

This prospective study of sickness absence because of back pain among office workers provides only modest support for an atherothrombotic component in the aetiology and or prognosis of back pain. However, two factors are likely to bias these findings toward null; the young age of participants at baseline and the lack of distinction between different types of back pain. Examining short ( $\leqslant 7$ days) and long (>7 days) spells of absence separately in men and women, we found, in age adjusted models, that low apo A1 and smoking were associated with back pain. This effect was consistent across four of four and three of four of the duration-sex cells respectively. A further six factors were associated with back pain in two of the duration-sex cells: low exercise and high 
BMI, waist-hip ratio, triglycerides, insulin and $\mathrm{Lp}(\mathrm{a})$. On full adjustment (for age, BMI, employment grade and back pain at baseline), each of these factors retained a statistically significant effect in at least one duration-sex cell. Because of the public health importance of back pain, these novel observations merit further investigation to see whether a subgroup of atherothrombotic back pain can be identified.

The major strength of the Whitehall II study lies in the unique combination of detailed cardiovascular exposure measurements with a validated ${ }^{31}$ measure of back pain outcome. No other prospective population based study investigating back pain aetiology has a comparable range of biochemical cardiovascular risk factors; conversely existing cardiovascular cohort studies have, at best, only crude measures of self reported back pain. Being an occupational cohort, the Whitehall II study is able to examine spells of sickness absence and these represent not only back pain morbidity (experience of symptoms), but also, in a working population, functional disability. Separate analyses of short and long spells of absence give a measure of the severity and public health burden of back pain, although a pure distinction between aetiological and prognostic factors is not possible. Spells of sickness absence have the advantage of being timed episodes permitting analyses of rates. The observation that symptoms of back pain strongly predict subsequent sickness absence, specifically because of back pain, supports the validity of this case definition. Clearly in the absence of a case definition of back pain caused by lumbar artery disease suitable for use in population studies, risk factor associations will tend to be biased towards unity.

However, the major limitation of this study relates to the temporal sequence between putative risk factor and spells of back pain sickness absence. Although Whitehall II is prospective in design, some of the risk factors - waist-hip ratio, triglycerides, insulin, $\mathrm{Lp}(\mathrm{a})$-were measured only at follow up and not at baseline. The definition of an incident (first lifetime) episode of back pain is problematic, being subject to recall bias. How then can we discount the possibility that back pain at baseline was the cause rather than the consequence of increased risk factor levels? It is plausible that participants with back pain at baseline might take less exercise with consequent increase in waist-hip ratio and BMI, followed by disturbances of lipid and carbohydrate metabolism. Indeed if this were true it would still be of public health interest, offering a potential mechanism for the reported association between back pain and subsequent ischaemic heart disease mortality.

There are three lines of evidence that suggest that back pain is unlikely to cause increased risk factor levels. Firstly, self reported back pain was not related to exercise at baseline, nor did it predict BMI, waist-hip ratio apo AI or triglycerides at follow up. Secondly, adjustment of associations by baseline back pain gives a measure of new spells of back pain and this
KEY POINTS

- Clinical and pathological studies suggest that atherothrombotic lumbar arteries may cause back pain.

- This is the first epidemiological study systematically examining this hypothesis.

- Biological (for example, apo AI) and behavioural (for example, smoking) atherothrombotic risk factors predicted sickness absence because of back pain in a cohort of office workers.

- Further research is required to identify population subgroups of atherothrombotic back pain.

adjustment had little effect on the estimates. Thirdly, as one of the factors associated with risk of back pain- $\mathrm{Lp}(\mathrm{a})$ is largely genetically determined, ${ }^{35}$ with few reported environmental correlates-it is unlikely that back pain could influence levels.

We examined 23 behavioural and biological risk factors for vascular disease in relation to sickness absence because of back pain. Given the paucity of published data with which to specify hypotheses and the need to avoid the problem of multiple comparisons, we used a relatively conservative measure of consistency of effect. We suggest that a risk factor that showed an effect in men and women for both short and long spells of absence may be less likely to be explained by chance or confounding than a risk factor showing an effect in only one duration-sex cell. As there were fewer long than short spells of absence and fewer spells in women than men, this test of consistency may be too conservative. The lack of statistical significance may merely reflect low power to detect plausible effects. A more stringent test of consistency of effect-for example requiring risk factors to demonstrate dose response relations-should be considered in further research.

Few other population studies have examined biochemical risk factors for back pain. Two cross sectional studies in men found no association between total cholesterol ${ }^{12}$ or lipid sub-fractions ${ }^{36}$ and back pain. The effect of low apo AI observed in this study was not confounded by minor psychiatric morbidityassociated in some studies with both cholesterol $^{37}$ and in others with back pain ${ }^{38}$-or by employment grade. Triglycerides were associated with short and long spells of sickness absence because of back pain in men in fully adjusted models with rate ratios of 1.53 (1.1, $2.1)$ and $1.75(1.0,3.2)$ respectively.

Unmeasured physical and ergonomic exposures could confound the observed associations. However, the variation in such exposures in this wholly office based cohort is unlikely to be large. Furthermore the finding that adjustment for civil service employment gradewhich is likely to be related to such unmeasured exposures - had in general only a small effect makes such confounding less probable. A possible explanation of these findings is that underlying exposures such as work or non-work 
stressors lead to low back pain ${ }^{31}$ and to atherothrombotic risk factors. ${ }^{28}{ }^{39}$ In other words both back pain and atherothrombotic risk factors may share some common antecedents.

The four risk factors most consistently associated with predicting subsequent vascular disease events are cholesterol, smoking, blood pressure, and pre-existing vascular disease. ${ }^{40}$ Two of the most robust risk factors for atherothrombotic disease-hypertension and preexisting coronary heart disease-did not predict back pain in this study. However, it is well recognised that some risk factors show stronger associations in specific sites, for example, smoking and peripheral arterial disease, blood pressure and carotid disease, cholesterol and coronary disease. Likewise lumbar arterial disease could be associated with its own pattern of risk factors.

These results provide some evidence in a working population for an atherothombotic component in the pathophysiology of back pain. Given the public health importance of back pain and the lack of success in identifying effective preventive interventions, ${ }^{41}$ further research might fruitfully concentrate on (a) the extent to which the biological and behavioural risk factors identified here and in other studies interact with ergononomic, physical, and psychosocial risk factors (b) more detailed noninvasive measurement of atherothrombotic disease in different arterial territories in subjects with and without back pain (c) the extent to which a subgroup of atherothrombotic back pain can be identified.

We thank all participating civil service departments and their welfare, personnel and establishment officers; the Civil Service Occupational Health Serivce: Dr Elizabeth McCloy, Dr George Sorrie and $\mathrm{Dr}$ Adrian Semmence; the Civil Service Central Monitoring Service and Dr Frank O'Hara; the Council of Civil Service Unions and all participating civil servants. We would like to thank all members of the Whitehall II study team. The work of Amanda Feeney and Jenny Head was crucial in the preparation of the sickness absence data.

Funding: the study was supported by grants from the Institute for Work and Health, Toronto, Ontario, Canada and the Volvo Research Foundation, Sweden; Medical Research Council, Health and Safety Executive, British Heart Foundation, National Heart Lung and Blood Institute (2RO1 HL36310), Agency for Health Care Policy and Research (5 RO1 HS06516), the National Institute on Aging (RO1 AG1319602) the New England Medical Centre-Division of Health Improvement the Department of Health and the John D and Catherine T MacArthur Foundation Research Network on Catherine T MacArthur Foundation Research Network on Successful Midlife Development. Michael Marmot is supported by an MRC Research Professorship. Eric Brunner and Conflicts of interest: none.

1 Frank JW, Pulcins IR, Kerr MS, et al. Occupational back pain-an unhelpful polemic [review]. Scand $\mathcal{f}$ Work Environ Health 1995;21:3-14.

2 Skovron M. Epidemiology of low back pain. Ballieres Clin Rheumatol 1992;6:559-73.

3 Walsh K, Varnes N, Osmond C, et al. Occupational causes of low-back pain. Scand $\mathcal{F}$ Work Environ Health 1989;15:54

4 Deyo R, Rainville J, Kent D. What can the history and physical examination tell us about low back pain? f $A M A$ 1992;268:760-5.

5 Jensen MC, Brant-Zawadzki MN, Obuchowski N, et al. Magnetic resonance imaging of the lumbar spine in people without back pain. N Engl F Med 1994;331:69-73.

6 Kauppila LI. Hypothesis: Can low-back pain be due to lumbar artery disease? Lancet 1995;346:888-9.

7 Kauppila LI, Penttila A, Karhunen PJ, et al. Lumbar disc degeneration and atherosclerosis of the abdominal aorta. Spine 1994;19:923-9.

8 Kaupila LI. Prevalence of stenotic changes in arteries supplying the lumbar spine. A postmortem angiographic supplying the lumbar spine. A postmortem angiographich
study on 140 subjects. Ann Rheum Dis 1997;56:591-5.
9 Maigne JY, Treuil C, Chatellier G. Altered lower limb vascular perfusion in patients with sciatica secondary to disc herniation. Spine 1996;21:2531-8.

10 Jayson MIV, Keegan A, Million R, et al. Fibrinolysis and back pain. Lancet 1984;2:1186-7.

11 Battié M, Bigos S, Fisher L. A prospective study of the role of cardiovascular risk factors and fitness in industrial back pain complaints. Spine 1989;14:141-7.

12 Svensson $\mathrm{H}$, Vedin A, Wilhelmsson C, et al. Low back pain in relation to other diseases and cardiovascular risk factors. Spine 1983;8:277-85.

13 Boshuizen H, Verbeek J, Boroersen J, et al. Do smokers get more back pain? Spine 1993;28:35-40.

14 Deyo R, Bass J. Lifestyle and low back pain. The influence of smoking and obesity. Spine 1989;14:501-6.

15 Brage S, Bjerkedal T. Musculoskeletal pain and smoking in Norway. F Epidemiol Community Health 1996;50:166-9.

16 Penttinen J. Back pain and risk of fatal ischaemic heart disease: 13 Year follow-up of Finnish Farmers. BMF 1994; 309:1267-8.

17 Heliövaara M, Makela M, Aromaa A, et al. Low back pain and subsequent cardiovascular mortality. Spine 1995;20: 2109-11.

18 Kauppila LI, McAlindon T, Evans S, et al. Disc degeneration/back pain and calcification of the abdominal aorta. A 25 year follow up study in Framingham. Spine 1997;22:1642-7.

19 Marmot MG, Davey Smith G, Stansfeld SA, et al. Health inequalities among British Civil Servants: the Whitehall II study. Lancet 1991;337:1387-93.

20 Brunner EJ, Marmot MG, White IR, et al. Gender and employment grade differences in blood cholesterol, apolipoproteins and haemostatic factors in the Whitehall II poproteins and haemostatic factors in

21 Rose G, Blackburn H, Gillum RF, et al. Cardiovascular survey methods. Geneva: WHO, 1982.

22 Mount JN, Kearney EM, Rosseneu M, et al. Immunoturbidimetric assays for serum apolipoproteins A1 and B using Cobas Bio centrifugal analyser. F Clin Pathol 1988;41:4714.

23 Friedewald WT, Levy RI, Fredrickson DS. Estimation of the concentration of low-density lipoprotein cholesterol in plasma, without use of the preparative ultracentrifuge. Clin Chem 1972;18:499-502.

24 Beksinska M, Yea L, Brunner EJ. Whitehall II study manual for screening examination 1991-93. London: DEPH, 1995.

25 WHO Study Group. Diabetes mellitus: Report of a WHO Study Group. Geneva: World Health Organization, 1985.

26 Clauss A. Gerinnungsphysiologische Schnellmethode zur Bestimmung des Fibrinogens. Acta Haematol 1957;17:23746.

27 Brozovic M, Stirling Y, Harricks C, et al. Factor VII in an industrial population. Br f Haematol 1974;28:381-91.

28 Brunner EJ, Marmot MG, Nanchahal K, et al. Social inequality in coronary risk: central obesity and the metabolic syndrome. Evidence from the Whitehall II study. Diabetologia 1997;40:1341-9.

29 Whitty CJM, Brunner EJ, Shipley MJ, et al. Differences in biological risk factors for cardiovascular disease between three ethnic groups in the Whitehall II study. Atherosclerosis 1999;142:279-86.

30 Office Population Censuses and Surveys. General Household Survey 1977. London: HMSO, 1979.

31 Hemingway H, Shipley M, Stansfeld S, et al. Back pain sickness absence, psychosocial work characteristics and employment grade: a prospective study in office workers. Scand 7 Work Environ Health 1997;23:121-9.

32 North F, Syme SL, Feeney A, et al. Explaining socioeconomic differences in sickness absence: the Whitehall II study. BMF 1993;306:361-6.

33 Khaw KT. Where are the women in studies of coronary heart disease? BMF 1993;306:1145-6.

34 Davey Smith G, Phillips AN. Confounding in epidemiological studies: why "independent" effects may not be all they seem. BMF 1992;305:757-9.

35 Boerwinkle E, Leffert CC, Lin J, et al. Apolipoprotein(a) gene accounts for greater than $90 \%$ of the variation in plasma lipoprotein(a) concentrations. F Clin Invest 1992; 90:52-60.

36 Welin L, Larsson B, Svardsudd K, et al. Serum lipids, lipoproteins and musculoskeletal disorders among 50- and 60 -year old men. An epidemiologic study. Scand $\mathcal{F}$ Rheumatol 1978;7:7-12.

37 Brown SL. Lowered serum cholesterol and low mood. BMF 1996;313:637-8.

38 Leino P, Magni G. Depressive and distress symptoms as predictors of low back pain, neck shoulder pain, and other musculoskeletal morbidity: a 10 year follow up of metal industry employees. Pain 1993;53:89-94.

39 Brunner E, Davey Smith G, Marmot M, et al. Childhood social circumstances and psychosocial and behavioural factors as determinants of plasma fibrinogen. Lancet 1996;34: $1008-13$

40 Marmot MG, Elliott P. Coronary heart disease epidemiology: from aetiology to public health. London: Oxford University Press, 1992

41 Lahad A, Malter AD, Berg AO, et al. The effectiveness of four interventions for the prevention of low back pain. fAMA 1994;272:1286-91. 